\title{
Transition to Adulthood for Youth with Disability: Issues for the Disabled Child and Family
}

\author{
Sudha Pandey *\& Shalini Agarwal ** \\ Research Scholar $^{*} \&$ Assistant Professor ${ }^{* *}$ \\ Department of Human Development and Family Studies, School for Home Sciences. Babasaheb Bhimrao \\ Ambedkar University, Lucknow.
}

\begin{abstract}
Transitioning is a time of change...
Youth face many changes and challenges as they move into adulthood, and for those who have been involved in various social welfare systems, these changes can be even more profound. The transition to adulthood and selfsufficiency can be challenging for any young person Like all young people, youth with disabilities face a number of stage of life transitions at the time they leave school and enter into the adult world. In recent years, there has been increasing recognition of the need to improve transition planning and support for young disabled people moving into adulthood, and to co-ordinate this support across a wide range of agencies, including health and social care, youth services, leisure, careers guidance, housing, education, benefits and employment services. In many parts of the country, people are working hard within voluntary and statutory sectors to meet this challenge. This article provides a conceptual framework about transition process and planning services for youth with disabilities.
\end{abstract}

Key Words: Transition, Youth, Adulthood, Disabled.

\section{Introduction}

The process of moving from childhood to adulthood is a difficult time for the youngest people. We make many transitions in our lives, but perhaps the one with the most far- reaching consequences is the transition into adulthood.' (Heslop et al,2002). This paper provides an overview of the prominent challenges currently faced by disabled young people. For many young people, leaving school or leaving home at this lifestage can mean huge changes in the environments where they live and spend their days. Of all groups with disability, the groups about which we know the least are disabled adolescents and young adults. This category encompasses both individuals in the age range labeled by UNICEF as "adolescents" (those between age of 10 18 ) and by the United Nations as "youth" (19-24). Subgroups within this category have distinct issues and concerns. The needs of a disabled 12 year old are very different than for a disabled 21 year old, however, for the purposes of this paper, they have been brought together because of the large number of issues and concerns they share. In transition between childhood and adulthood, these are the years when young people are expected to acquire skills, go through physical and psychological maturation and assume a social identify that will enable them to fully participate in their communities. Adolescents and young adults are grouped together and discussed jointly because they share common characteristics: they are often bypassed both by the programme and policies designed for disabled children and left out of advocacy initiatives and employment schemes targeted for adults with disability. Nor are their unique social, psychological, education and economic needs addressed by programmes designed to reach their non-disabled age-mates. Alongside the many physical and emotional changes that are part and parcel of adolescence, growing up also involves changes in roles, relationships, expectations and status - within family, amongst friends and within the wider community of home, school and work Current evidence about the transition to adulthood for youth with disabilities indicates that the process is extremely challenging. While there are substantial personal challenges such as physical, sensory, cognitive and communicative limitations, environmental barriers often present the most significant challenges for transition (Committee on Disability in America, 2007; Stewart et al. 2006).

\section{What Difficulties Can Arise At Transitions?}

The transition process can have multiple and complex impacts on youth with disabilities and their families. Issues can arise concerning social, occupational, and leisure roles, which may affect youths' selfesteem, self-concept, and sense of hope. They may experience difficulty in establishing fulfilling relationships and may have lost long-term relationships established in high school. They may experience difficulties in finding meaningful involvement in leisure roles and occupational roles, such as volunteerism, employment, or college or university attendance. Compared to youth without disabilities, youth with disabilities are one third 
less likely to be employed and one half less likely to participate in post secondary education (Peraino, 1992). Transitions affect both youth and their families. Parents can feel the stress of this launching stage for their children (Hallum, 1995) and may experience difficult emotional times when the future fails to live up to their expectations for their child.

\section{Feelings and emotions at transition}

Transition to adulthood is an emotionally demanding time. Not only are young people experiencing body changes that can cause emotional 'ups and downs', but external changes (such as leaving school) and the need to make important decisions about the future can be stressful and challenging for young people and their families. Emotional and psychological transition for young people has attracted very little academic attention. Many young people with learning difficulties will remain emotionally dependent on parents despite living independently, or may have conflict-ridden relationships with parents and support staff. Achieving emotional autonomy may be particularly difficult for learning disabled young people (Zetlin \& Turner, 1985, quoted in Clegg et al, 2001).Access to emotional support is essential at transition, for young people and families alike. Morgan (2003) outlines how the families emotional resilience of young people with disability might been courage at transition, and suggests that these factors are crucial:

- Support for the family and working with the family from an early age.

- Attention to physical health needs - these can affect mental health.

- Support for communication - being listened to, having a communication passport.

- Awareness of bullying, abuse and loss - support through these times and to have their feelings acknowledged.

- Schools, colleges and transition - should play a role in providing options.

\section{Transition and the family}

Families of young people with learning difficulties play a major role at transition. The literature highlights the essential nature of family involvement and the difference it makes to effective transition. Yet this is often overlooked by professionals, to the extent that family involvement and families' views and input are frequently absent from the transition planning process (Morris, 2002). And McNair and Rusch (1991) go as far as to state that in the absence of special funding or special projects, the single most important in successful transition is the parent. Stories from youth and parents indicate that they feel like they "have been dropped off a cliff" once they reach adulthood Youth with disabilities have reported that they have similar aspirations to their counterparts without disabilities, but there are more obstacles during the transition to adult life. The literature often reports youth with disabilities having limited opportunity to participate in assessment and planning services, particularly in relation to educational and career planning (Hitchings et al. 2001).

\section{Key barriers that many young disabled people and their families still face-}

- Young people, their families and those working with them frequently lack easily accessible, comprehensive, up-to-date information about options, choices and possibilities

- Many young disabled people have no experience of an independent social life and few opportunities to make friends: they spend most of their time with family or paid careers and have no independent access to transport, telecommunications, or personal assistance over which they have choice and control.

- Families, and the young person's role within their family and local community, are very important to young disabled people but this is often not recognised by services. Young people may be moved some distance from their family and community simply to have their support needs met.

- Many young people who have significant communication impairments reach adulthood without proper assessment of their communication needs or concerted action to meet these needs.

- Many further education, training and work experience placements are considered to be 'care' placements for young disabled people, rather than a way of gaining qualifications or paid employment.

- The availability of supported employment (support to enable a young person to do a paid job alongside nondisabled workers) varies geographically and projects are often financially insecure.

- The varied sources of assessment, funding and provision of equipment and support make it difficult for young people to get equipment and support as and when they need it.

- Young disabled people rarely get the opportunity to move into a home of their own. Instead they are more likely to be 'slotted into' available service provision.

- Young people with high levels of support needs often move into residential or nursing care as they reach adulthood, and sometimes have little or no contact with young people their own age 


\section{Factors that Influence Transition-}

Environmental Factors: Barriers- Environmental barriers described in the literature are:

- The People's attitudes towards youth with different types of disabilities and ethnic status in general influences all aspects of transition and also interacts with many of the other environmental factors (Annable et al. 2004);

- Lack of knowledge about options and understanding of disability-related needs of youth by service providers, educators, parents and community members affects a young person's transition process negatively (Hitchings et al. 2001);

- Lack of opportunities, choices and experiences in childhood through adolescence and the transition itself has a profound impact on adult outcomes (Foster and MacLeod 2004)

- Primary environment the environment of the family can also pose barriers, such as socioeconomic status (SES). However, one study has found that SES has a smaller impact on youth with disabilities than those with no disabilities. Other family factors include parents' low expectations for the future (Chambers, Hughes and Carter 2004) and their lack of knowledge and information to help their young adult (Learning Disabilities Association of Canada 2007).

\section{Complexity-}

Recent studies have found that some youth with disabilities may become involved in criminal behavior and substance abuse, which increases the complexity of their situation and often results in negative outcomes of school failure and unemployment. Disability interacts with other forms of disadvantage, for example, ethnicity, poverty and immigrant status, but knowledge about the exact nature and process of these interactions among different groups of youth is limited. Studies have also found that having a disability and completing secondary education positively influences future employment outcomes but how this interaction occurs is also not known.

Domains of Transition -Many articles and resources focus on one specific or particular domain of transition. The domains relate to the main 'events' of the transition to adulthood for all young people. The primary domains identified in the literature include employment, education and training, independent living, and social/community life.

Employment domain -Within the employment domain, most literature is on "school to work". For example, education-to-lab our market pathways indicate that the presence of a long-term condition is a 'hindrance' to further education and thus to future employment.Some young people with disabilities have reported choosing the type of employment based on the ability of the employer to provide equity and accommodations. Strategies to address school-work transitions are also described in the literature. They include the need for inter professional and inter-system efforts; real-life experiences and opportunities for work through situated education; and the development of student-focused strategies such as collaboration and data-driven decisionmaking for service providers (National Secondary Transition Technical Assistance Centre (NSTTAC) 2008).

Education domain -This domain includes both secondary and post-secondary systems. A great deal of literature in this domain is from the United States. The literature stresses the importance of starting transition planning and services early in high school when services are free and accessible, and youth have time to participate in valuable experiences (Izzo and Lamb 2003). Recent articles also challenge educators and others to focus more on transition planning and career development than just job finding skills (Shroedel and Geyer 2000). Other reviews identify the importance of post-secondary education for successful adult outcomes and the need for careful transition planning to ensure success (Wagner et al.2006).

Living domain - Most of the literature about the transition out of the parents' home is focused on 'independent living' services and supports (Hendey and Pascall 2001). The literature from several countries supports the need for more research in this area, and the need to identify a range of options for young people (and their parents) who want to live away from the family home (Blacher 2001; Hendey and Pascall 2001).

Social and community life domain - This domain covers a broad range of transition outcomes and activities, including community recreation and leisure activities, social relationships, marriage and parenting. Literature reviews address this domain when examining transition to adulthood broadly, and they identify this domain as essential to successful and satisfying adult living (Lehman et al.2002). In many cases this domain is acknowledged as one that does not receive enough attention. Further research in this area is needed.

\section{PROGRAMMES FOR YOUNG PEOPLE WITH DISABILITY}

There are an increasing number of programmes that address the specific needs of young 
people with disabilities, organized by government agencies, private voluntary organizations, religious organizations and community groups.

\section{TRANSITIONAL PROGRAMMES: SCHOOL TO WORK}

Programmes that provide a solid grounding for disabled young people, particularly as they enter the workplace, fall roughly into one of two categories - those that are separate from and primarily or exclusively for individuals with disability, and those that are inclusive, allowing disabled young people to participate alongside their non-disabled peers. Ideally both types of programmes should be available. Separate income producing programmes have existed for years, often in the form of sheltered workshops in both the developed and developing world The programme assists young people with disabilities with training and support to enter mainstream vocational training programmes, and helps them find a job or use their skills to start a business small loans of capital have allowed women with disability to invest in small-scale income generating endeavour's (e.g., a sewing machine or chickens) which have resulted in real social and financial independence.

INCLUSIVE PROGRAMMES- Separate programmes for disabled young people are not the only answer. All too often, young people with disabilities are not included in broader village wide regional, and national development schemes targeted to all young people in the general community. Given the prevalence of disability, some $10 \%$ of any group of young people receiving skills or job training should be young people with disability. If these young people with disability are missing from a skills building initiative or local development project then the question for whomever is organising the programme is: where are they and why are they missing from a programme designed to benefit the general population? Innovative examples are beginning to appear, such as the World Bank's recently initiated Velugu project which is intended to systematically integrate disabled people into the mainstream of rural poverty alleviation programmes, but more is needed.

\section{Intervention efforts}

1. Individualized work-based experiences:- These experiences could include combinations of the following: career exploration, job shadowing, volunteer work, internships, apprenticeships, and paid employment.

2. Youth empowerment:- Youth empowerment refers to the acquisition of self-knowledge by youth so that they may direct and advocate for their life choices.

3. Family supports:- Family supports are necessary to actively engage family members in the intervention to gain a better understanding of project services, workincentives(includingthe

SSA waivers described below), and other related services that might benefit the youth.

4. System linkages:- Two types of system linkages are useful in transition interventions. The first is the linkage of academic coursework with work based experiences. Such a linkage often makes coursework relevant to students, keeps them engaged in academic curricula so they are less likely to drop out of school, and/or creates an applied learning environment.

5. Social and health services:- Many youth with disabilities may need social and health services to facilitate their success in the classroom, in the community, and on the job. This meta service is commonly referred to as "case management," "wrap-around services," or "care coordination."

6. SSA work incentive waivers:- The waivers are intended to encourage youth to initiate or increase their work activity and to increase their earnings or continue with their education.

7. Benefits counseling:- Care must be taken to design and deliver counseling in such a way as to avoid encouraging youth who are not receiving disability benefits to apply for them and to avoid encouraging youth who are receiving benefits to limit their earnings. In addition, counseling must encourage the accurate reporting of earnings to SSA to avoid benefit overpayments and the consequences of the subsequent recovery of those overpayments.

\section{Best Practice Guidelines-}

Best Practice Guidelines for the transition to adulthood for youth with disabilities have been written using the words of youth, parents, community members, service providers, educators and researchers in Ontario, Canada. The Guidelines are organized into six main themes that emerged from comprehensive literature reviews, consensus meetings and focus groups with key stakeholders.

- Collaborative initiatives and policies are necessary supports for the transition to adult life. 
- Building capacity of people and communities will enhance transition process.

- The role of the "Navigator" within communities facilitates capacity building.

- Information and resources are available to all involved in the transition process.

- Education is a critical component of any transition strategy.

- Ongoing research and evaluation provides the evidence needed for success, different types of disabilities, and their families.

\section{Conclusion-}

This analysis of the evidence-based literature on transition to adulthood for youth with disabilities indicates that there has been a growth in the number of studies and review articles on this topic in the past eight years. The literature provides a clear picture of the experiences, challenges and desired outcomes of youth with Best Practice Guidelines for the transition to adulthood for youth with disabilities.. It is evident that there is a great deal of knowledge about separate 'components' of transition: the different perspectives and experiences; different types of transition; different domains; and various factors (often separated in the literature into barriers and supports). Challenges also exist between a holistic/interactional approach to transition and disability that most people, organizations and governments aspire to, and current organizational and system differences and needs. Researchers, organizations and services will need to put aside the view that 'our group is different/special' and recognize that, while there will always be unique situations and needs, more progress in studying this complex issue and providing appropriate services and supports may take place if everyone works together.

\section{References}

[1]. Annable G, Watters C, Stienstra D, Symanzik S, Tully BL, Stuewer N. 2003. Students with disabilities. Transition from postsecondary education to work. Phase I report. Winnipeg, Manitoba: Canadian Centre of Disability Studies.

[2]. Blacher J. 2001. Transition to adulthood: Mental retardation, families, and culture. American Journal of Mental Retardation 106(2):173-88.

[3]. Chambers CR, Hughes C, Carter EW. 2004. Parent and sibling perspectives on the transition to adulthood. Education and Training in Developmental Disabilities 39(2):79-94.

[4]. Foster S, MacLeod J. 2004. The role of mentoring relationships in the career development of successful deaf persons. Journal of Deaf Studies and Deaf Education 9(4):442-58.

[5]. Hallum, A. (1995, January). Disability and the transition to adulthood: Issues for the disabled child, the family, and the paediatrician. Current Problems in Pediatrics, 25, 12-50.

[6]. Heslop, P., Mallett, R. Simons, K. \& Ward, L. (2002) Bridging the Divide at

[7]. Transition. What Happens for Young People with Learning Difficulties and their

[8]. Hendey N, Pascall G. 2001. Disability and transition to adulthood. Achieving independent living. [Internet]. [cited 2009 June 16]. 2001. Available from: http://eprints.nottingham.ac.uk/845/1/Hendey__Pascall_FINAL.pdf.

[9]. Hitchings WE, Luzzo DA, Ristow R, Horvath M, Retish P, Tanners A. 2001. The career development needs of college students with learning disabilities: In their own words. Learning Disabilities Research and Practice 16(1):8-17.

[10]. Izzo MV, Lamb P. 2003. Developing self-determination through career development activities: Implications for vocational rehabilitation counselors. Journal of Vocational Rehabilitation 19:71-8.

[11]. Lehman CM, Clark HB, Bullis M, Rinkin J, Castellanos LA. 2002. Transition from school to adult life: Empowering youth through community ownership and accountability. Journal of Child and Family Studies 11(1):127-41

[12]. McNair, J. \& Rusch, R. (1991) 'Parent involvement in transition programs', Mental Retardation, 29 (2), pp. $93-101$.

[13]. Morgan, H. (2003) 'Count us in: the inquiry into meeting the mental health needs of young people with learning disabilities', Tizard Learning Disability Review 8 (3), pp. 37-43.

[14]. Morris, J. (2002) 'Young disabled people moving into adulthood', Foundations, York, Joseph Rowntree Foundation, June 2002

[15]. National Secondary Transition Technical Assistance Centre (NSTTAC) 2008. Team planning tool for State capacity building: Secondary education and transition services. Charlotte NC. [Internet] [Cited 2009 June 28. 2009. Available from: http://www.nsttac.org/pdf/state_cap_building_tool.pdf.

[16]. Organization for Economic Co-Operation and Development. Disabled Youth: From School to Work. Paris, 1991.

[17]. Peraino, J. (1992). Post-21 studies: How do special education graduates fare? In P. Wehman (Ed.), Lif ebeyond the classroom: Transition strategies for young people with disabilities (pp. 21-70). Baltimore:Brookes

[18]. Shroedel JG, Geyer PD. 2000. Long-term career attainments of deaf and hard of hearing college graduates: Results from a 15-year follow-up study. American Annals of the Deaf 145(4):303-14.

[19]. Wagner M, Davis M. 2006. How are we preparing students with emotional disturbances for the transition to young adulthood? Findings from the National Longitudinal Transition Study - 2. Journal of Emotional and Behavioral Disorders 14(2):86-98.

[20]. Zetlin and Turner, 1985 quoted in Clegg et al, 2001. 